The Egyptian Journal of Hospital Medicine (July 2019) Vol. 76 (7), Page 4608-4615

\title{
Ultrasonographic Enthesis Evaluation in Patients with Recurrent Acute Anterior Uveitis with and without Spondyloarthropathy Asaad Nooreldin ${ }^{*}$, Mohamed Ismail Abdelkareem², Ahmed Moslam Ibrahim², and Amr Mohamed Mahmoud ${ }^{2}$ Departments of ${ }^{1}$ Ophthalmology and ${ }^{2}$ Rheumatology, Faculty of Medicine, Al-Azhar University, Assiut, Egypt \\ "Corresponding Author: Asaad Nooreldin, Tel: +2010263666024, Email: asaad_nooreldin@yahoo.com
}

\begin{abstract}
Background: spondyloarthritis $(\mathrm{SpA})$ is a group of chronic diseases recognized by arthritis and extraarticular lesions e.g. uveitis, enthesitis, dermatological affection. About 35\% of SpA patients may present with recurrent attacks of acute anterior uveitis (AAU).

Purpose: it was to detect whether patients with idiopathic recurrent AAU who were positive or negative for Human Leukocyte Antigen B27 (HLA-B27) had a frequency of enthesis lesions compared to that seen in patients with SpA.

Patients and Methods: a prospective study of enthesis evident on musculoskeletal ultrasound examination was done on sixty patients and twenty controls, the eighty were categorized into 4 groups; group 1 included 20 patients with known SpA group 2 included 20 with recurrent AAU HLA-B27 positive and didn't have SpA aspects group 3 included 20 with recurrent AAU HLA-B27 negative and didn't have SpA and group 4 included 20 healthy controls. Using Madrid Sonography Enthesitis Index (MASEI) twelve enthesis locations were assessed in each participant.

Results: a total of 960 entheses sites were examined by ultrasonography in all 80 participants. The MASEI cut-off limit of $\geq 18$ points was $75 \%, 60 \%, 45 \%$, and $10 \%$ of the participants in the 4 groups; respectively. The MASEI score was significantly higher in groups $1 \& 2$ than in groups $3 \& 4$. The differences between the two groups were statistically significant. Conclusion: a high percent of HLA-B27 positive patients with idiopathic recurrent AAU without characteristics of SpA have enthesis lesions with about percent to those seen in patients with known SpA.
\end{abstract}

Keywords: Enthesis, ultrasound, acute anterior uveitis, and spondyloarthritis.

\section{INTRODUCTION}

Spondyloarthropathies are a group of systemic inflammatory troubles share a general manifestation which include arthritis of the axial and/or distal joints, inflammatory backache, enthesitis, skin and gut manifestations ${ }^{(\mathbf{1})}$. The term spondyloarthritis (SpA) includes ankylosing spondylitis (AS), psoriatic arthritis (PsA), SpA associated with enteropathic (inflammatory bowel disease), reactive arthritis (RA), and undifferentiated SpA (i.e. a presentation with typical manifestations of SpA without any manifestations of any the previously mentioned four subtypes) ${ }^{(2)}$. Remarkably, the Assessment of Spondyloarthritis International Society (ASAS) classification criteria $^{(3)}$ have recommended that recurrent attacks of acute anterior uveitis (AAU) in patients who known to be positive for Human Leucocytic Antigen B27 (HLA-B27) must be included in the series of SpA. An early diagnosis of SpA is important, however it looks that early diagnosis is still challenging for physicians. There is about 5 years delay in the diagnoses of SpA according to different literature ${ }^{(4)}$.

In addition, axial SpA keeps going to be working for years. Furthermore, it doesn't disappear over time; most of functional disability happens in the early few years in the course of the disease ${ }^{(4)}$. AAU is the most common feature of uveitis; it may precede other clinical manifestations, and be the key presentation for diagnosis of $\mathrm{SpA}^{(5)}$.

About half of the patients presenting with acute recurrent anterior uveitis are positive for HLA-B27 and more than half of these HLA-B27 positive patients have undiagnosed $\mathrm{SpA}^{(6)}$. Spondyloarthritis, is considered one of the most frequent rheumatic diseases, its prevalence about $0.5 \%-1.9 \%$ in general population ${ }^{(7)}$.

The most common systemic disease associated with acute anterior uveitis is spondyloarthritis, on the other side, the most frequent non-skeletal manifestation among patients with SpA is uveitis ${ }^{(7,8)}$. So, eye affection may be the key manifestation of undiagnosed rheumatologic disease ${ }^{(7)}$. It is estimated that more than $1 / 3$ of patients with spondyloarthropathy have SpA. On the other side, half of AAU cases are idiopathic regardless of their link to HLA-B2 $7^{(9)}$.

Enthesis is the zones where tendon, ligament, or joint capsule attached at a bone to facilitates easy joint motion and assist in transmission of tensile load from soft tissues to bone ${ }^{(\mathbf{1 0})}$. Inflammation of enthesis, a specific manifestation of SpA, is believe to be the hallmark lesion in the disease ${ }^{(\mathbf{1 1})}$. Enthesitis occurs due to inflammation at adhesion parts of tendons to bones and comprises the main pathophysiological and clinical features of $\mathrm{SpA}^{(\mathbf{1 1})}$. The lower extremity enthesis is more commonly affected than upper extremity entheses because the lower entheses are more exhibited to mechanical exertion $^{(\mathbf{1 2})}$.

Imaging studies are more sensitive and specific than clinical examination in the diagnosis of enthesitis, and even ultrasonography might be superior to MRI in detection of early signs of enthesopathy ${ }^{(\mathbf{1 3})}$. Ultrasonography (US) the best tool to evaluate periarticular soft tissue as it is sufficient for discovering both early (edema and thickening) and late changes 
(erosion and enterophytosis) $^{(\mathbf{1 4})}$. Further, it's a safe, and easily ready, inexpensive and reproducible manoeuvre ${ }^{(\mathbf{1 4})}$. There are many semi-quantitative methods of ultrasonographic assessment of enthesitis, but the Madrid Sonography Enthesitis Index (MASEI) is the most practical score. The score has a high sensitivity, specificity values for the diagnosis of SpA regardless of the presence of other clinical features ${ }^{(15)}$.

This index bilaterally assesses 6 enthesis sites for each patient (superior and inferior of calcaneus, tibial tuberositas, superior and inferior parts of patella, olecranon tuberosity ${ }^{(\mathbf{1 6})}$. Using ultrasonography, enthesopathy is recognized by loss of regular fibrillar structure, increased tendon thickness or focal changes of tendon insertion, bone overgrowth or erosions, calcific deposits in B mode and increased vascularization in power Doppler mode (PD) ${ }^{(15,17)}$.

The total score of the MASEI is affected by acute and chronic enthesis changes and must be considered in the evaluation. Acute changes are increased vascularization (PD), and the presence of bursitis, while chronic changes are increased thickness, structural changes, and presence of calcification or erosions ${ }^{(\mathbf{1 8})}$.

\section{AIM OF THE STUDY}

It is to investigate whether patients with idiopathic recurrent AAU who were positive or negative for Human Leukocyte Antigen B27 (HLA-B27) had a frequency of enthesis lesions similar to that seen in patients with $\mathrm{SpA}$.

\section{PATIENTS AND METHODS}

A prospective blinded, case control study design was chosen to conduct this research. The study included eighty subjects. It was carried out at the Ophthalmology and Rheumatology departments, Al-Azhar University Hospital at Assiut, between June 2015 and December 2017.

\section{Ethical and approval considerations:}

This study was performed according to the declaration of Helsinki and was approved by the Ethical Committee of the Al-Azhar University. An informed written consent was taken from all participants.

\section{Patients and controls:}

There were 60 patients included in our study; they were divided into three groups. Also, we randomly selected 20 healthy subjects as a control group. The study groups were subdivided as follows:

- Group 1: Twenty patients with AAU with SpA group included fourteen patients with AS, four patients with PsA, two patients with ReA.

- Group 2: Twenty patients with AAU and positive for HLA-B27 and without any clinical manifestations or radiological findings of SpA.
- Group 3: Twenty patients with AAU and negative for HLA-B27 and without any clinical manifestations or radiological findings of SpA.

- Group 4: Twenty healthy control subjects matched with same age and sex.

\section{Inclusion criteria:}

Patients aged 18-45 years, with recurrent attacks of idiopathic AAU, and without any articular signs of SpA.

\section{Exclusion criteria:}

Patients with positive history of trauma, operation or infection in the entheses area (evaluated by US) and patients with other rheumatological diseases were excluded from the study.

All patients had $\geq 2$ flares (attacks) of uveitis and the diagnosis of uveitis was determined at Ophthalmology clinic by the author.

Patients were diagnosed as AAU according to the Standardized Uveitis Nomenclature ${ }^{(\mathbf{1 9})}$ (SUN) classification and classified as having idiopathic recurrent AAU by Ophthalmologist using the International Uveitis Study Group ${ }^{(20)}$ (IUSG) classification system. AAU was defined as a sudden onset of ocular pain, redness, photophobia and lacrimation associated with anterior chamber cells and had $\geq 2$ previous attacks, and the duration of which was less than 3 months.

Patients were diagnosed as AAU according to the Standardized Uveitis Nomenclature ${ }^{(19)}$ (SUN) classification and classified as carrying recurrent AAU idiopathic by an ophthalmologist using the international classification system of the Uveitis Study Group (IUSG) ${ }^{(\mathbf{2 0})}$. AAU was defined as a sudden onset of eye pain, redness, photophobia and tears associated with anterior chamber cells and was subjected to previous attacks $\geq 2$, and its duration was less than 3 months.

\section{Musculoskeletal ultrasonography (MSUS):}

A Real-time Conventional B-mode US and power Doppler (PD) examinations were performed to all groups by 2 rheumatologists well trained in musculoskeletal US (Toshiba Xario200 with linear probe) with a linear transducer 7-13 MHz. The sonographers were blinded with regard to the clinical data, and the included persons asked not to give any data to the US examiners.

Abnormalities were specified using the MASEI Score. The MASEI Scores are as follows: tendon structure; tendon thickness and bursa 1 point. Power D0ppler signal (PD) and erosion scored as 0 or 3 points. Calcification was scored $0-3$ according to its size. The final total MASEI score was calculated by adding up all scores. With the minimum score is 0 , the maximum score is 136. A value of 18 points was used as the cutoff point to differentiate $\mathrm{SpA}$ cases from controls. 
Ultrasound examination was carried out 2 days after clinical examination for all subjects.

- Sites of examination: the following entheses were evaluated bilaterally according to the MASEI: inferior pole of the calcaneus, superior pole of the calcaneus, tibial tuberosity, inferior part of the patella, superior part of the patella, olecranon tuberosity.

- Technique: each tendon was scanned in both the longitudinal and transverse planes. Knee enthesis examination was done while the patient in the supine position with the knee flexed to $70^{\circ}$. The tendon Achilles and plantar aponeurosis were evaluated with the patient in the prone position and the feet in $90^{\circ}$ of flexion. The arm should be flexed to $90^{\circ}$ while examining the triceps insertion.

- Entheses were evaluated by US for the following: structure, thickness, erosions, calcifications, bursitis, and power Doppler signal (according to MASEI).

\section{Statistical analysis}

A statistical analysis of the data was performed using SPSS- version 20 software program. Categorical data parameters were presented in the form of frequency and percentage. Chi-square test was used to compare the percentages of cases within each group with a MASEI score greater than or equal to the cutoff value of 18 points. A descriptive analysis was performed for all study variables, presenting the absolute and relative frequencies in case of qualitative variables (Chi-square test was used), as well as the mean with standard deviation (Mean $\pm \mathrm{SD}$ ) in the case of the continuous variables (ANOVA test was used). Probability (P-value) level was assumed significant if $<0.05$, highly significant if $\mathrm{P}$-value was $<0.001$, and $\mathrm{P}$ value was considered insignificant if $\geq 0.05$.

\section{RESULTS}

From a total number of 160 patients attended to the outpatient clinics and inpatients of both departments all of them were complaining of AAU; 108(67.5\%) patients had SpA, 28(17.5\%) patients had AAU HLAB27 positive without SpA, and $24(15 \%)$ patients had AAU HLA-B27 negative without SpA.

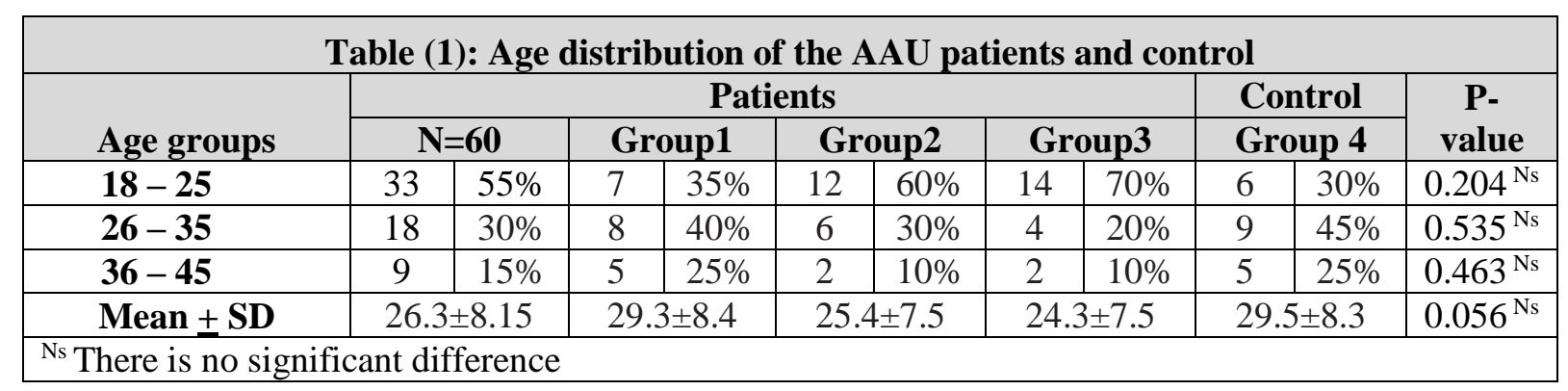

Table (2): Gender distribution in AAU patients and control

\begin{tabular}{|c|c|c|c|c|c|c|c|c|c|c|c|}
\hline \multirow{3}{*}{$\begin{array}{r}\text { Gender } \\
\text { Male }\end{array}$} & \multicolumn{8}{|c|}{ Patients } & \multirow{2}{*}{\multicolumn{2}{|c|}{$\begin{array}{l}\text { Control } \\
\text { Group4 } \\
\end{array}$}} & \multirow{3}{*}{$\begin{array}{c}\begin{array}{c}\text { P- } \\
\text { value }\end{array} \\
0.247^{\mathrm{Ns}}\end{array}$} \\
\hline & \multicolumn{2}{|c|}{$\mathrm{N}=60$} & \multicolumn{2}{|c|}{ Group1 } & \multicolumn{2}{|c|}{ Group2 } & \multicolumn{2}{|c|}{ Group3 } & & & \\
\hline & 45 & $75 \%$ & 18 & $90 \%$ & 15 & $75 \%$ & 12 & $60 \%$ & 8 & $40 \%$ & \\
\hline Female & 15 & $25 \%$ & 2 & $10 \%$ & 5 & $25 \%$ & 8 & $40 \%$ & 12 & $60 \%$ & $0.044^{*}$ \\
\hline
\end{tabular}

*There is a statistically significant difference at p-value $<0.05$

${ }^{\mathrm{N} s}$ There is no significant difference

The study examined sixty AAU patients and twenty normal subjects as a control group with their ages ranged from 18 to 45 years (Mean \pm SD $26.3 \pm 8.15$ years). Forty-five patients $(75 \%)$ were male and fifteen patients $(25 \%)$ were female. The disease duration ranged from (1-9) years (5.3 \pm 4.15 years).

(Tables 1\&2).

We found that males are more frequently affected than females with spondyloarthropathy in all studied groups 


\begin{tabular}{|c|c|c|c|c|c|c|c|c|c|c|c|}
\hline \multicolumn{12}{|c|}{ Table (3): Cut off value of MASEI score in both AAU patients and controls } \\
\hline \multirow[b]{2}{*}{ MASEI score } & \multicolumn{8}{|c|}{ Patients } & \multirow{2}{*}{\multicolumn{2}{|c|}{$\begin{array}{l}\text { Control } \\
\text { Group4 } \\
\end{array}$}} & \multirow{2}{*}{ P-value } \\
\hline & \multicolumn{2}{|c|}{$N=60$} & \multicolumn{2}{|c|}{ Group1 } & \multicolumn{2}{|c|}{ Group2 } & \multicolumn{2}{|c|}{ Group3 } & & & \\
\hline$<18$ point & 24 & $40 \%$ & 5 & $25 \%$ & 8 & $40 \%$ & 11 & $55 \%$ & 18 & $90 \%$ & $0001 *$ \\
\hline$\geq 18$ point & 36 & $60 \%$ & 15 & $75 \%$ & 12 & $60 \%$ & 9 & $45 \%$ & 2 & $10 \%$ & $0.001^{n}$ \\
\hline
\end{tabular}

\begin{tabular}{|c|c|c|c|c|c|c|}
\hline \multicolumn{7}{|c|}{ Table (4): Mean \&range of MASEI score among AAU patients and controls } \\
\hline \multirow{2}{*}{ Mean } & No=60 & Group1 & Group2 & Group3 & Groutrol & P- \\
& value \\
\hline Mean \pm SD & $22 \pm 10.34$ & $30.7 \pm 12.72$ & $18.9 \pm 4.34$ & $16.4 \pm 5.36$ & $10.3 \pm 5.88$ & \multirow{2}{*}{$0.001 *$} \\
\hline Range & $6-48$ & $10-48$ & $12-26$ & $6-24$ & $2-20$ & \\
\hline *There is a statistically significant difference at p-value $<0.01$ \\
\hline
\end{tabular}

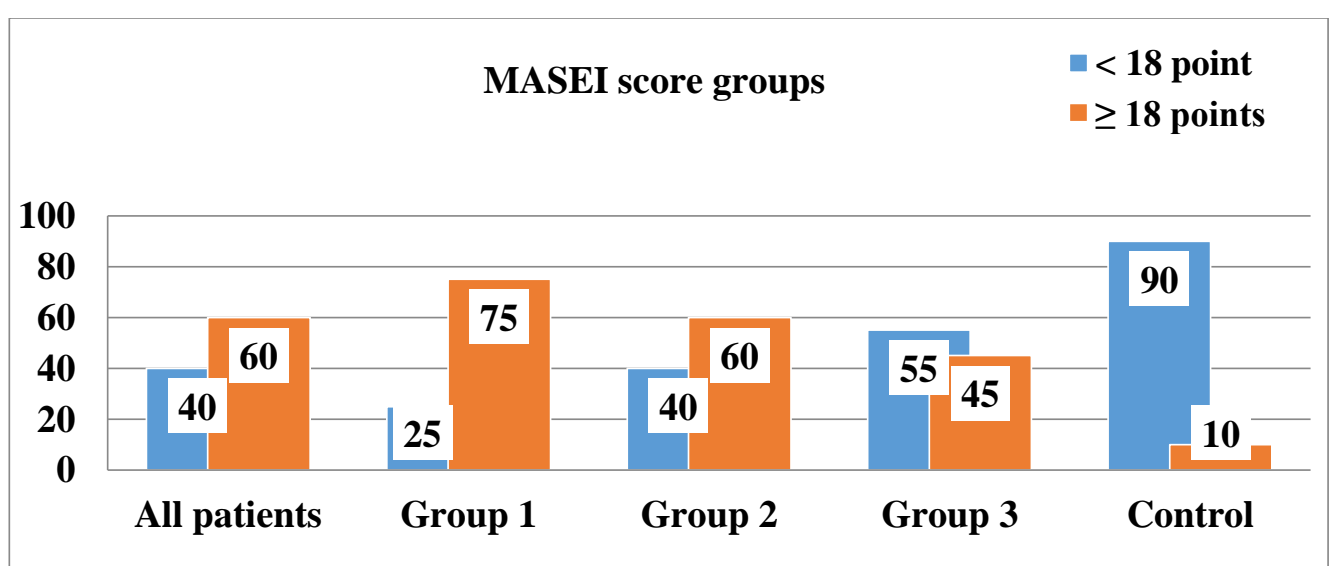

Figure (1): Cut off value of MASEI score in both AAU patients and control.

The MASEI score cutoff value of 18 points, which discriminates between SpA patients and controls, it was about $75 \%$ in patients with SpA (group 1), 60\% of the HLA-B27 positive patients with AAU (group 2), 45\% of the HLA-B27 negative patients with AAU (group 3), and it was only $10 \%$ of the subjects in control group (group 4 ) (Tables $\mathbf{3} \& \mathbf{4}$ and Figure 1).

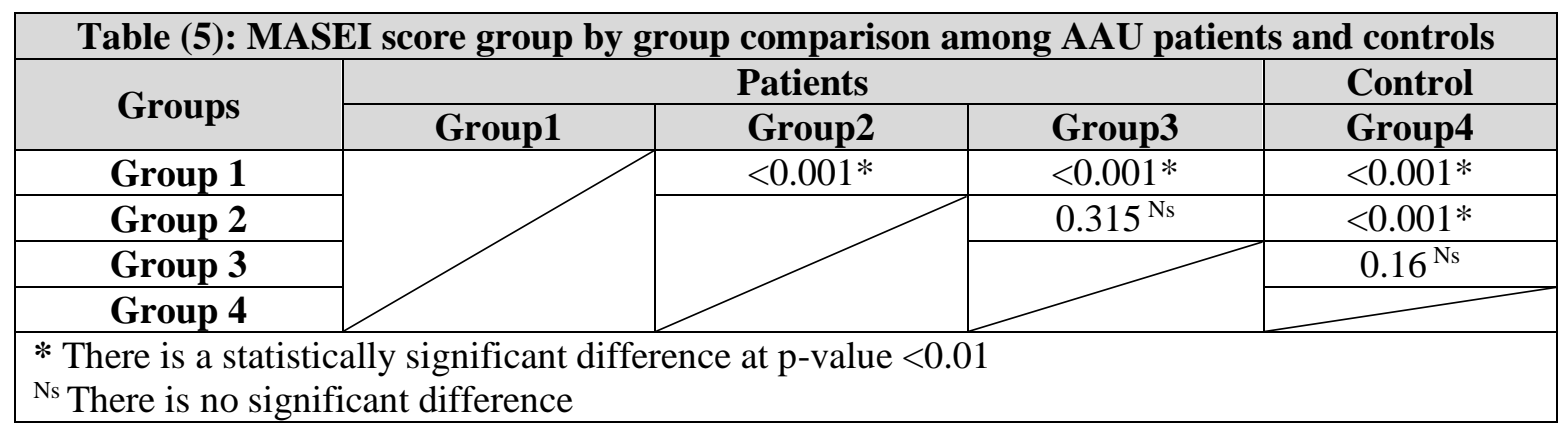

Table (5) shows MASEI score (group by group) P-value comparison. The overall differences between groups in the mean MASEI score were found to be statistically significant. Patients with SpA (group 1) have a significantly different score from patients in group 2, group 3 and control healthy group. Patients in group 2 didn't have a significantly different score than patients in groups 3 ; however groups $2 \& 3$ have a significantly different score than control healthy group. 


\begin{tabular}{|c|c|c|c|c|c|c|c|c|}
\hline Table (6): Number of AAU attacks distribution in AAU patients \\
\hline AAU attacks & $\mathbf{N o}=\mathbf{6 0}$ & Group1 & Group2 & \multicolumn{2}{c|}{ Group3 } \\
\hline $\mathbf{2 - 3}$ & 30 & $50 \%$ & 7 & $35 \%$ & 10 & $50 \%$ & 13 & $65 \%$ \\
\hline $\mathbf{4 - 5}$ & 24 & $40 \%$ & 10 & $50 \%$ & 8 & $40 \%$ & 6 & $30 \%$ \\
\hline$\geq \mathbf{6}$ & 6 & $10 \%$ & 3 & $15 \%$ & 2 & $10 \%$ & 1 & $5 \%$ \\
\hline P-value & $<0.001 * *$ & $0.157^{\mathrm{Ns}}$ & $0.074^{\mathrm{Ns}}$ & $0.004 * *$ \\
\hline
\end{tabular}

\begin{tabular}{|c|c|c|c|c|c|c|c|c|}
\hline \multicolumn{9}{|c|}{ Table (7): Laterality of AAU flare } \\
\hline Laterality & \multicolumn{2}{|c|}{ No $=60$} & \multicolumn{2}{|c|}{ Group1 } & \multicolumn{2}{|c|}{ Group2 } & \multicolumn{2}{|c|}{ Group3 } \\
\hline Unilateral & 36 & $60 \%$ & 10 & $50 \%$ & 12 & $60 \%$ & 14 & $70 \%$ \\
\hline Bilateral & 15 & $25 \%$ & 6 & $30 \%$ & 6 & $30 \%$ & 3 & $15 \%$ \\
\hline Alternating & 9 & $15 \%$ & 4 & $20 \%$ & 2 & $10 \%$ & 3 & $15 \%$ \\
\hline P-value & \multicolumn{2}{|c|}{$<0.001 * *$} & \multicolumn{2}{|c|}{$0.247^{\mathrm{Ns}}$} & \multicolumn{2}{|c|}{$0.022 *$} & \multicolumn{2}{|c|}{$0.002 * *$} \\
\hline $\begin{array}{l}\text { **There is a statistically si } \\
* \text { There is a statistically sig } \\
\text { Ns } \text { There is no significant di }\end{array}$ & ice : & $\begin{array}{l}\text { o-value } \\
\text {-value }\end{array}$ & & & & & & \\
\hline
\end{tabular}

The unilateral or unilateral alternating acute anterior uveitis was the most common presentation in about $75 \%$ of the patients (Tables 6\&7).

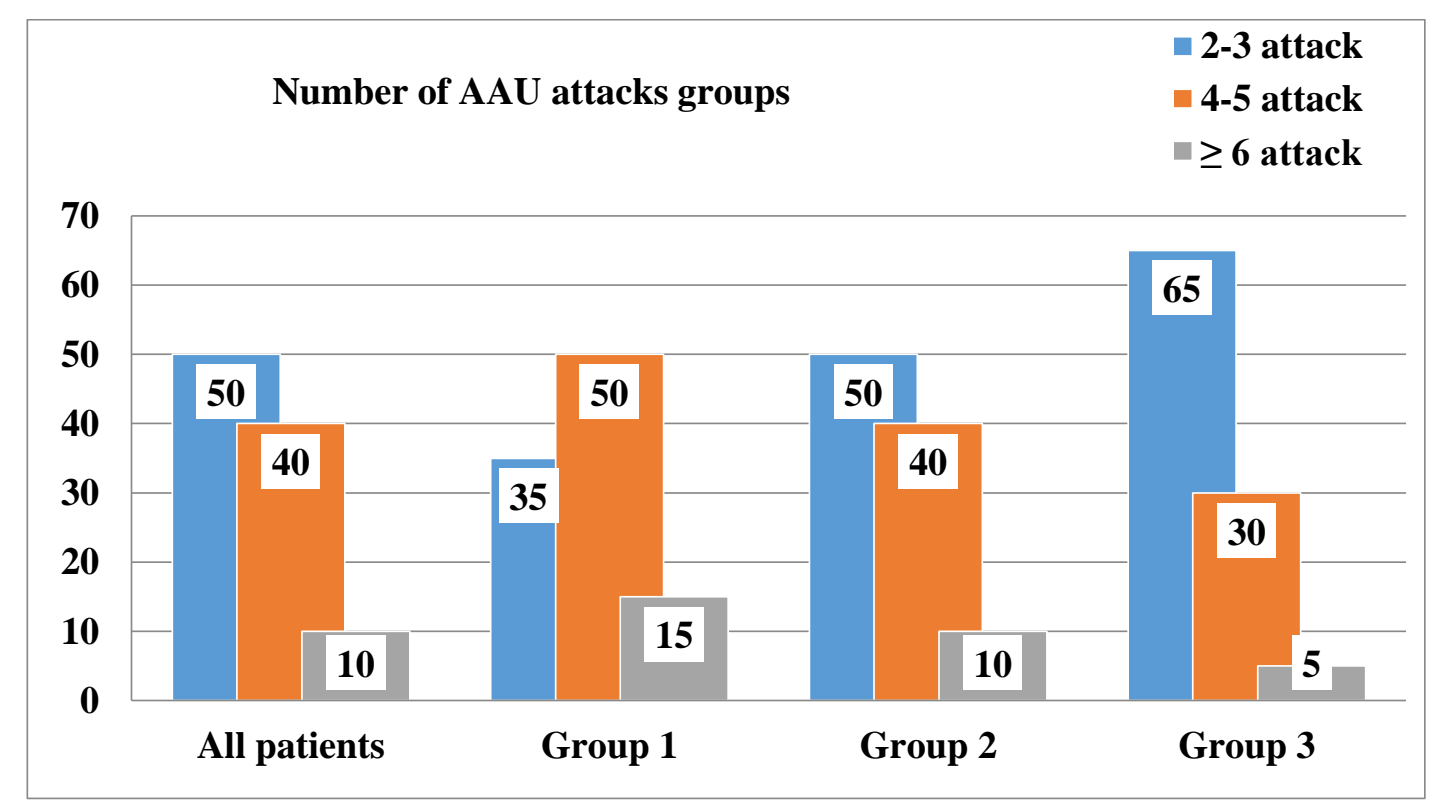

Figure (2): Number of AAU attacks distribution in AAU patients

AAU was the initial manifestation to be recognized by the physician in groups 2 and 3 with no other signs of SpA. About 55\% of patients in groups 2 and 3 have undiagnosed SpA and ware first diagnosed as SpA by having recurrent $\mathrm{AAU}$ and enthesis score of $\geq 18$ point without any other $\mathrm{SpA}$ manifestations.

No statistically significant difference was found between SpA (group 1) and non-SpA patients (groups 2\&3) as regard the laterality or the number of previous attacks of AAU (Figures $\mathbf{2} \& \mathbf{3}$ ).

When AAU patients with HLA-B27 positive compared with HLA-B27 negative patients we found that they nearly have the same age and gender. 


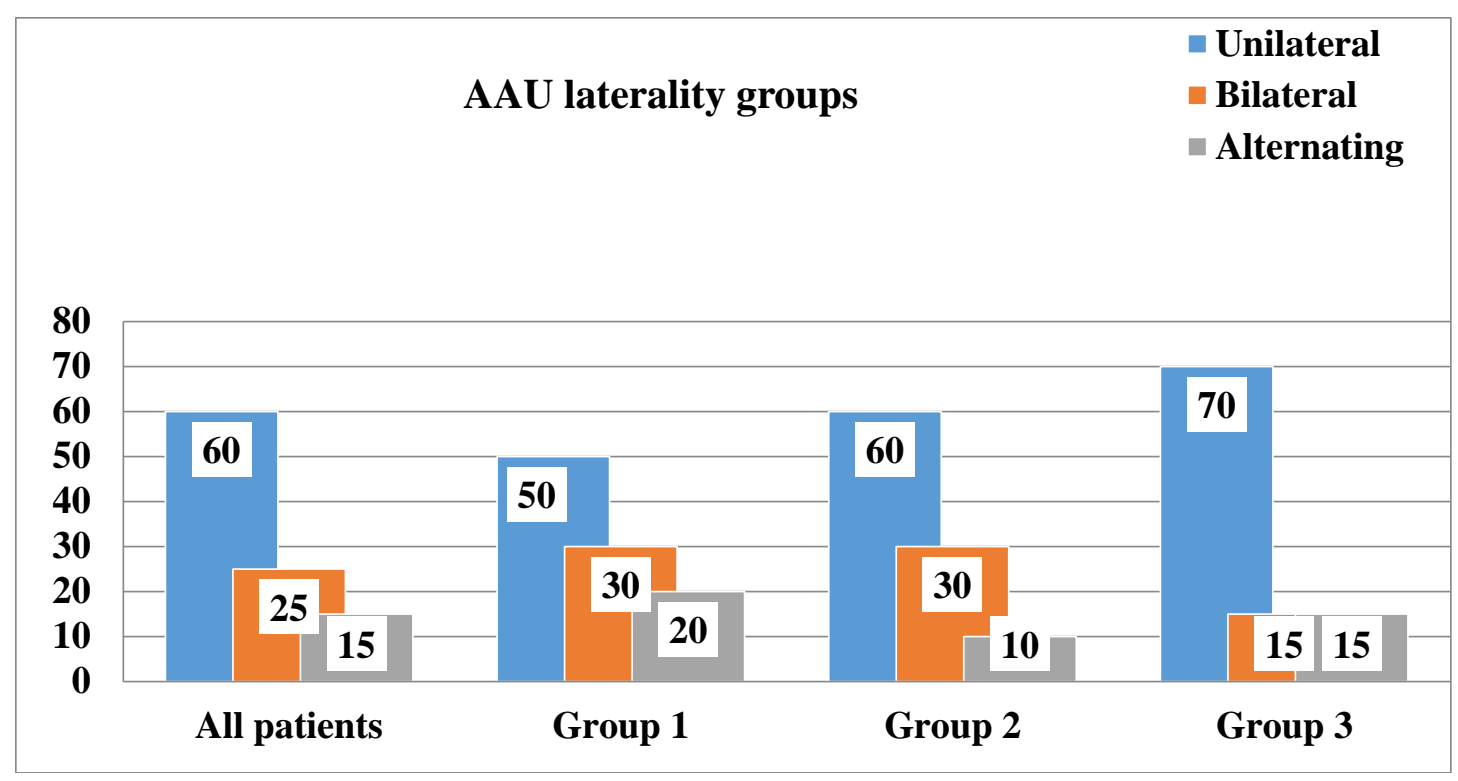

Figure (3): Laterality of AAU flare

\section{DISCUSSION}

The aim of this study was to demonstrate that patients with recurrent idiopathic AAU who were either positive or negative for HLA-B27 with no other clinical manifestations of $\mathrm{SpA}$ had enthesis lesions pattern similar to that seen in patients with SpA and so that they may be considered as having an abortive, atypical, or sub-clinical mild form of SpA.

In this study our ultrasonographic results showed that patients with recurrent AAU who were positive for HLA-B27 had sub-clinical enthesis changes similar to those established in patients with recognized $\mathrm{SpA}$. These findings assume that these patients (HLAB27 positive patients with AAU, but without any clinical and/or radiologic signs of SpA) might have subclinical or incomplete form of SpA. According to MASEI score it was found, a statistically significant difference in the mean MASEI score between the four groups included in our study, which come with the study

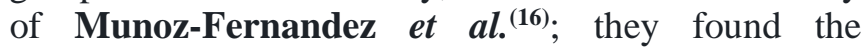
similar findings. In our study it was found a statistically significant difference between SpA AAU patients group and both AAU HLA-B27 positive and HLA-B27 negative without $\mathrm{SpA}$ patients groups as regard the enthesis MASEI index.

However, in study done by Munoz-Fernandez et $\boldsymbol{a l} .^{(16)}$ didn't have any significantly different score between SpA and HLA-B27 positive patients, but they found a significant difference between SpA and HLAB27 negative patients as we found between them.in the present study didn`t find a statistically significant difference between AAU HLA-B27 positive without SpA patients group and AAU HLA-B27 negative without SpA patients group regarding enthesopathy score.

In this study, $60 \%$ and $45 \%$ of asymptomatic patients with AAU who were positive or negative for HLA-B27, respectively, had enthesis lesions on US examination similar to that seen in known SpA patients.

We observed that about $55 \%$ of patients with AAU had previously undiagnosed SpA. However, a study done by Rosenbaum ${ }^{(21)}$ cleared that $84 \%$ of their patients with AAU had SpA, most of them previously undiagnosed. Previous studies have revealed that about $25 \%$ of patients presented with uveitis have undiagnosed $\mathrm{SpA}$, furthermore about half of them were diagnosed with $\mathrm{SpA}$ after an attack of uveitis ${ }^{(22)}$. In another study, it has shown that about $71.2 \%$ of HLAB27-positive uveitis patients had $\mathrm{SpA}^{(\mathbf{2 3})}$.

Haroon et al. ${ }^{(24)}$ found that $40 \%$ of patients with presumed idiopathic AAU had undiagnosed SpA. In this study it was found that HLA-B27 positive AAU is more likely to be more severe, of shorter duration, higher recurrence rate, and with more complications than HLA-B27 negative AAU. These patients require more care with both medical and surgical management. The present study revealed, that the majority of AAU HLAB27 positive patients presented with unilateral AAU involvement $(60 \%)$, while $30 \%$ presented with bilateral involvement and only $10 \%$ AAU had alternating involvement, with a statistically significant difference. While AAU HLA-B27 negative had unilateral (70\%), $15 \%$ had bilateral, and $15 \%$ presented with alternating unilateral and bilateral involvement also this difference statistically significant. 
In agreement with our study, study done by Tuncer et $\boldsymbol{a l}^{(\mathbf{2 5 )}}$ revealed that $66 \%$ of HLA-B27 positive patients had unilateral AAU, bilateral alternating AAU in $27 \%$, and only $7 \%$ presented with bilateral simultaneous AAU. Meanwhile, $57 \%$ of HLAB27 negative patients had unilateral AAU, 17\% had alternating bilateral $\mathrm{AAU}$, and $26 \%$ had bilateral simultaneous AAU.

Also, Loh and Acharya ${ }^{(26)}$ reported results similar for the present study regarding the laterality of uveitis. However, in study done by Wakefield et al. $^{(27)}$ found that AAU HLA-B27 positive were more likely to be unilateral AAU involvement, in comparison to AAU HLA-B27 negative, were tended to be bilateral AAU involvement.

We observed that the highest recurrence rate was among AAU SpA patients group and it was also higher in AAU HLA-B27 positive without SpA than AAU HLA-B27 negative without SpA patients, with a statistically significant difference. Various previous studies reported the same results of a higher recurrence rate of uveitis among HLA-B27 positive patients than among HLA-B27 negative patients without a systemic disease ${ }^{(27-29)}$.

In comparison to the present study, in study done by Tuncer $\boldsymbol{e t} \boldsymbol{a l} .^{(25)}$ there was no significant difference in the mean recurrence rate between HLAB27 positive and negative patients. However, frequency of attacks in one year follow up was higher in the AAU HLA-B27 negative than in the AAU HLA-B27 positive, but with statistically insignificant difference ${ }^{(25)}$. This difference may be due to the difference in the studied populations.

\section{CONCLUSION}

This study revealed that a significant enthesopathy was found in HLA-B27 positive patients presented with only recurrent AAU and had no other clinical manifestations of SpA. These enthesis lesions were similar to those found in SpA patients and those patients might have an abortive or limited form of SpA. HLA-B27 negative patients had less enthesis lesions. It was recommended that ultrasonographic evaluation of enthesopathy should be included in the clinical examination of patients presented with recurrent attacks of AAU in the outpatient clinic. Also, it is recommended that development of a clinical protocol aimed to close collaboration between the ophthalmologist and rheumatologist for effective diagnosis and treatment of patients presented with AAU and for identifying systemic diseases.

\section{REFERENCES}

1. Smith WM (2013): Gender and Spondyloarthropathy Associated Uveitis. J Ophthalmol., 213:1-6.

2. Rosenbaum JT (2015): Uveitis in spondyloarthritis including psoriatic arthritis, ankylosing spondylitis, and inflammatory bowel disease. Clin Rheumatol., 34:9991002.

3. Rudwaleit M, van der Heijde D, Landewe R, Listing J, Akkoc N, Brandt J et al. (2009): The development of Assessment of Spondyloarthritis international Society classification criteria for axial spondyloarthritis (part II): validation and final selection. Ann Rheum Dis., 68:777783.

4. Nakashima Y, Ohishi M, Okazaki K, Fukushi JI, Oyamada A, Hara D et al. (2016): Delayed diagnosis of ankylosing spondylitis in a Japanese population. Mod Rheumatol., 26:421-425.

5. Fernández-Melón J, Muñoz-Fernández $\mathrm{S}$, Hidalgo $\mathrm{V}$, Bonilla-Hernán G, Schlincker A, Fonseca A et al. (2004): Uveitis as the initial clinical manifestation in patients with spondyloarthropathies. J Rheumatol., 31:524-527.

6. Brewerton DA (1985): The genetics of acute anterior uveitis. Trans Ophthalmol Soc., 104:248-249.

7. Zeboulon N, Dougados $M$ and Gossec $L$ (2008): Prevalence and characteristics of uveitis in the spondyloarthropathies: a systematic literature review. Ann Rheum Dis., 67:955-959.

8. Canouï-Poitrine F, Lekpa FK, Farrenq V, Boissinot V, Hacquard-Bouder C, Comet D et al. (2012): Prevalence and factors associated with uveitis in spondylarthritis patients in France: results from an observational survey. Arthritis Care Res. (Hoboken), 64:919-924.

9. Martin TM, Smith JR and Rosenbaum JT (2002): Anterior uveitis: Current concepts of pathogenesis and interactions with the spondyloarthropathies. Curr Opin Rheumatol., 14(4):337-341.

10. Apostolakos J, Durant TJ, Dwyer CR, Russell RP, Weinreb JH, Alaee F et al. (2014): The enthesis: a review of the tendon-to-bone insertion. Muscles Ligaments Tendons J., 4: 333-342.

11. McGonagle D, Marzo-Ortega $\mathrm{H}$, O'Connor P, Gibbon W, Hawkey P, Henshaw K et al. (2002): Histological assessment of the early enthesitis lesion in spondyloarthropathy. Ann Rheum Dis., 61:534-537.

12. Balint PV, Kane D, Wilson H, McInnes IB and Sturrock RD (2002): Ultrasonography of entheseal insertions in the lower limb in spondyloarthropathy. Ann Rheum Dis., 61:905-910.

13. Kamel M, Eid $H$ and Mansour $R$ (2003): Ultrasound detection of heel enthesitis: a comparison with magnetic resonance imaging. J Rheumatol., 30:774-778.

14. Frediani B, Falsetti P, Storri L, Allegri A, Bisogno S, Baldi F et al. (2002): Ultrasound and clinical evaluation of quadricipital tendon enthesitis in patients with psoriatic 
arthritis and rheumatoid arthritis. Clin Rheumatol., 21:294-298.

15. De Miguel E, Cobo T, Munoz-Fernandez S, Naredo E, Uson J, Acebes JC et al. (2009): Validity of enthesis ultrasound assessment in spondylarthropathy. Ann Rheum Dis., 68:169-174.

16. Muñoz-Fernández S, De Miguel E, Cobo-Ibáñez T, Madero R, Ferreira A, Hidalgo M-V et al. (2009): Enthesis Inflammation in Recurrent Acute Anterior Uveitis without Spondylarthritis. Arthritis Rheum., 60:1985-1990.

17. Wakefield RJ, Balint PV, Szkudlarek M, Filippucci E, Backhaus M, D'Agostino MA et al. (2005): Musculoskeletal ultrasound including definitions for ultrasonographic pathology. J Rheumatol., 32:2485-2487.

18. Sullivan $C$ and FitzGerald OM (2010): Time to Diagnosis of Ankylosing Spondylitis in an Irish Cohort and the Effect on Work Disability. Arthritis Rheum., 62:555-561.

19. Jabs DA, Nussenblatt RB and Rosenbaum JT (2005): Standardization of Uveitis Nomenclature Working Group - Standardization of Uveitis Nomenclature for Reporting Clinical Data: Results of the First International Workshop. Am J Opphtalmol., 103:509-516.

20. Bloch-Michel $E$ and Nussenblatt RB (1987): International Uveitis Study Group Recommendations for the Evaluation of Intraocular Inflammatory Diseases. Am J Opphtalmol., 103: 234-235.

21. Rosenbaum JT (1989): Characterization of uveitis associated with spondyloarthritis. J Rheumatol., 16:792796.

22. Pato E, Bañares A, Jover JA, Fernandez-Gutierrez B, Godoy F, Morado C et al. (2000): Undiagnosed spondyloarthropathy in patients presenting with anterior uveitis. J Rheumatol., 27:2198-2202.

23. Juanola X, Loza Santamaria E, Cordero-Coma M (2016): Description and prevalence of spondyloarthritis in patients with anterior uveitis: the SENTINEL Interdisciplinary Collaborative Project. Ophthalmology, 123:1632-1636.

24. Haroon M, O'Rourke M, Ramasamy P, Murphy CC and FitzGerald $O$ (2015): A novel evidence-based detection of undiagnosed spondyloarthritis in patients presenting with acute anterior uveitis: the DUET (Dublin Uveitis Evaluation Tool). Ann Rheum Dis., 74:19901995.

25. Tuncer S, Adam YS, Urgancioglu $M$ and TugalTutkun I (2005): Clinical Features and Outcomes of HLA-B27 Positive and HLA-B27 Negative Acute Anterior Uveitis in a Turkish Patient Population. Ocular Immunol Inflammation, 13:367-373.

26. Loh AR and Acharya NR (2010): Incidence rates and risk factors for ocular complications and vision loss in HLA-B27 associated uveitis. J Ophthalmol., 150:534-542.

27. Wakefield D, Chang JH, Amjadi S, Maconochie Z, Abu El-Asrar A and McCluskey P (2011): What Is New HLA-B27 Acute Anterior Uveitis? Ocular Immunol Inflammation, 19:139-144.

28. Chung YM, Liao HT, Lin KC, Lin YC, Chou CT, Chen CH et al. (2009): Prevalence of Spondyloarthritis in 504 Chinese Patients With HLA-B27 Associated Acute Anterior Uveitis. Scand J Rheumatol., 38:84-90.

29. Wang Y, Lu X, Wang Y, Mao L, Gu Y, Chen P et al. (2012): Clinical Analysis of 240 Patients With HLA-B27 Associated Acute Anterior Uveitis. Eye Science, 27:169172. 